references later than 194I. There is a marked lack of uniformity in the bibliographies; four chapters have their new references simply tacked to the end of the old, in three cases with no dates. Some chapters use full references, some short; one even omits authors.

A reviewer must judge the completeness of a compendium on the subjects with which he is familiar. For Red Squill dosage we find only Winton (1927). Where are Munch, Silver and Horn (r 929), O'Connor, Buck and Fellers (1935), Stoll and Renz (1942) and many more far more detailed than Winton's paper? For fleas 'Pulex, Xenopsylla, Ctenocephalides and Ceratophyllus are common parasites of wild rats.' The species of three of these genera are never more than strays on rats. Xenopsylla contains the best-known plague fleas, but nowhere is plague even mentioned.

The books contains much information but has a number of shortcomings, not the least of which is its price.

R.B.F.

\section{DIAGNOSTIC TESTS FOR INFANTS AND CHILDREN}

By H. Behrendt, M.D. Pp. xvii + 529. London and New York: Interscience Publishers. 1949. $£ 3$.

As Dr. Behrendt says in his introduction, there has hitherto been no book of functional tests specially applicable to infancy and childhood, and he sets out to fulfil this need. He also appreciates the difficulty of what to put in and what to leave out. His book is four-fifths the biochemistry of these functional tests, while the remaining fifth contains sections on electrocardiography, electroencephalography, psychological testing and sundry other tests of function.

The bulk of the book on the application of biochemistry to clinical problems is excellent. Written for the practising clinician as well as the laboratory worker, each set of tests is preceded by a consideration of their application to children and followed by a paragraph on the interpretation of results. No attempt is made to give an exhaustive list of methods, and usually only one method is described simply and in a way which will appeal to British pathologists and research workers. The pediatric considerations and interpretation will be useful to physicians of all seniority and, in that the evaluation of the laboratory findings is critical and objective, it will help to give younger pediatricians a sense of proportion in their demands on laboratory time.

While such techniques as electroencephalography are clearly tests of function, and so fall within the defined ambit of the book, the reviewer found their inclusion faintly embarrassing, and he was in no position to appraise their worth. There is a section on rhesus serology which seems to be included unnecessarily and which will commend itself but little to English haematologists. Although the book is by an American author and presumably for an American public, one cannot help wondering when the good news of the Coombs test in haemotolog will be brought across the Atlantic.

As is to be expected, the book is admirable produced in a size not too big to be useful on the working bench. References at the end of eac無 section are adequate, although mostly not later than 1946 , and, with the exception of the inevitable misspelling of the name Fanconi, few errors of proof correction were noticed. The authoritative pres sentation in a single volume of a great deal o\$ knowledge not previously assembled will commend the book to all who practise pediatrics, and in $\mathscr{Q}$ work dealing so essentially with biochemical func $\vec{e}$ tion Dr. Behrendt might reconsider, in the future editions which are bound to be called for, the advisability of omitting some of the sections which are concerned with special side-lines.

I.A.B.C. $\frac{\text { 을. }}{3}$

RECENT ADVANCES IN CHEMOTHERAPY $\stackrel{\omega}{\circ}$ (Vol. I)

By G. M. FindLAY, C.B.E., Sc.D., M.D., F.R.C.P.

3rd edition. Pp. ix + 625. London: J. \& A을

Churchill, Ltd. 1950. $36 \mathrm{~s}$.

When Dr. Marshall Findlay produced the firs edition of this book in 1930 the subject was covereff in a relatively slim volume. The spectacula ${ }^{\circ}$ advances of the last 15 years now compel himgoexpand the work to four volumes. The fixser volume, now to hand, deals particularly with agemts effective against protozoal and helminthic infest. tions. The second volume will be devoted to malaria; the third to spirochaetal, bacterial ande virus infections, while the fourth will be devoted to general principles of chemotherapy and the use of antibiotics. Anyone possessing this set of manuals will clearly have a remarkably complete reference $\vec{B}$ library on the whole subject.

The subjects covered in volume $I$ are of interest not only to physicians practising in temperate climates, but are of particular value to those prac= tising in the tropics and also to veterinarians. The section on phenothiazine illustrates the thorough:manner in which the manual has been compiled 3 The action of this substance on intestinal wormsi was first discovered in 1938 . The section in the book is 20 pages long, $\mathrm{r} 20$ references are quoted and details are given of its use, not only in man, but also윽 in sheep, goats, cattle, pigs, horses, dogs, elephants $>$ and poultry. The medical reader will find fullo discussion of the pharmacological and therapeutic problems involved in such important diseases aso bilharziasis, trypansomiasis, amoebiasis and hel- $N$ minthic infections. The book will clearly find aN place on the shelves of interested specialists, while ${ }^{\omega}$ the general reader will find in it detailed accounts? of some fascinating therapeutic problems in tropicalo and comparative medicine. The value of the book would have been enhanced by a short introductory? paragraph outlining briefly the pathology and 0 clinical manifestations of the conditions of whicho the treatment is described in such detail. Very few $\overrightarrow{\mathbb{\Phi}}$ 